\title{
Topical niacinamide $4 \%$ and desonide $0.05 \%$ for treatment of axillary hyperpigmentation: a randomized, double-blind, placebo-controlled study
}

This article was published in the following Dove Press journal:

Clinical, Cosmetic and Investigational Dermatology

12 January 2013

Number of times this article has been viewed

Juan Pablo

Castanedo-Cazares'

Gabryela Lárraga-Piñones'

Adriana Ehnis-Pérez'

Cornelia Fuentes-Ahumada'

Cuauhtemoc Oros-Ovalle ${ }^{2}$

Bruce R Smoller ${ }^{3}$

Bertha Torres-Álvarez'

'Department of Dermatology,

${ }^{2}$ Department of Pathology, Hospital

Central Dr Ignacio Morones Prieto,

Universidad Autónoma de San Luis

Potosí, México; ${ }^{3}$ Department of

Pathology, University of Arkansas for

Medical Sciences, Little Rock, AK, USA
Background: Axillary hyperpigmentation is a frequent cause of cosmetic consultations in dark-skinned women from tropical areas, including Latin America. Currently, there is no widely accepted treatment for the disorder, but it is usually treated with bleaching agents because it is considered a variant of inflammatory hyperpigmentation. The purpose of this study was to assess the efficacy of niacinamide $4 \%$ and desonide $0.05 \%$ emulsions compared with placebo in the treatment of axillary hyperpigmentation.

Methods: Twenty-four women aged 19-27 years with hyperpigmented axillae (phototype III-V) were randomly assigned to receive the study treatments in the axillary region. Improvement was assessed at baseline, then clinically and by colorimetry 9 weeks later. Quantitative evaluation including melanin, inflammatory infiltrates, NKI/Beteb, CD1a, CD68, and collagen type IV content was performed by histochemistry and immunohistochemistry, assisted by computerized morphometric analysis.

Results: Both niacinamide and desonide induced significant colorimetric improvement compared with placebo; however, desonide showed a better depigmenting effect than niacinamide. A good to excellent response was achieved in $24 \%$ of cases for niacinamide, $30 \%$ for desonide, and $6 \%$ for placebo. We observed a marked disruption of the basal membrane in axillary hyperpigmentation and an inflammatory infiltrate that improved after treatment. Decreased pigmentation in the desonide-treated axillae was associated with recovery of disruption at the basal membrane.

Conclusion: Niacinamide and desonide showed depigmenting properties in women with axillary hyperpigmentation. These findings may be explained by their antimelanogenic and anti-inflammatory properties, respectively.

Keywords: post-inflammatory hyperpigmentation, niacinamide, desonide

\section{Introduction}

Post-inflammatory hyperpigmentation is one of the most common dermatological complaints in patients with colored skin. ${ }^{1}$ It results from an increase in melanin production or an abnormal distribution of this pigment in the epidermis and/or dermis after external injury. 2,3 Various inflammatory mediators, including prostaglandins, leukotrienes, thromboxanes, and reactive oxygen species, are known to induce activation of melanocytes. ${ }^{4,5}$ Destruction of the basal cell layer with incontinentia pigmenti and melanophages in the dermis has also been described. ${ }^{6,7}$

Axillary hyperpigmentation is a frequent dermatological problem in Latin-American females, although its exact frequency is unknown. Histopathologically, it is characterized
Correspondence: Bertha Torres-Álvarez Department of Dermatology, Hospital Central Dr Ignacio Morones Prieto, 2395 Carranza Ave, 78210, San Luis Potosí, SLP México

Tel +52 4448342795

Fax + 524448342795

Email torresmab@yahoo.com.mx 
by an increase in melanocytic activity and melanin deposits in both the epidermis and dermis, as well as an inflammatory infiltrate composed primarily of mononuclear cells and macrophages. ${ }^{8}$ These findings support the theory of axillary hyperpigmentation being a type of post-inflammatory hyperpigmentation, where the precipitating factors could be related to continuous irritation due to hair removal, ${ }^{8,9}$ cleansing, ${ }^{6}$ tight clothes, ${ }^{10}$ or use of antiperspirants. ${ }^{11}$ The higher prevalence of axillary hyperpigmentation in darker-skinned phototypes could also be related to specific innate traits in this group. ${ }^{1,8}$ These features may include the presence of genetically labile melanocytes that are easily destroyed by trauma and inflammation and/or an enhanced response to inflammatory stimuli with increased activity. ${ }^{1,5}$

Treatment of post-inflammatory hyperpigmentation is difficult and prolonged. Prevention and treatment of the underlying inflammatory condition are the first steps, followed by depigmenting interventions. Topical treatments used in post-inflammatory hyperpigmentation include hydroquinone (alone or in combination with other agents), ${ }^{12,13}$ mequinol, ${ }^{7,8}$ retinoids, ${ }^{14-16}$ azelaic acid, ${ }^{17}$ chemical peels, ${ }^{18,19}$ and light-based procedures. ${ }^{20}$ There are other topical treatments known for their depigmenting properties, including kojic acid, arbutin, niacinamide, and $\mathrm{N}$-acetyl glucosamine, but none of these have been studied in post-inflammatory hyperpigmentation. ${ }^{7}$

Niacinamide is an anti-inflammatory agent with depigmenting effects through inhibition of transfer of melanosomes from the melanocyte to the keratinocyte. ${ }^{21,22}$ The cutaneous bioavailability of niacinamide is relatively independent of the vehicle, showing good penetration and a maximum absorption rate at $48-72$ hours. ${ }^{23}$ In other hypermelanoses, such as melasma, a $4 \%$ formulation of niacinamide was able to reduce the epidermal melanin content and associated dermal inflammation, thereby improving the clinical hyperpigmentation. ${ }^{24}$ The beneficial effect of topical niacinamide has also been evident in acne, rosacea, and psoriasis, as well as in the prevention of photoimmunosuppression and photocarcinogenesis. $^{24}$

Topical steroids are capable of reducing the post-inflammatory hyperpigmentation that correlates closely with the severity of the preceding inflammation. ${ }^{25}$ Desonide is a synthetic, nonfluorinated, low potency corticosteroid used to treat cutaneous inflammation, and has a favorable safety profile. ${ }^{26}$

The biological effects of niacinamide and desonide may be helpful for the treatment of axillary hyperpigmentation. Therefore, the aim of this study was to compare the efficacy of topical niacinamide, desonide, and placebo in decreasing pigmentation and inflammation in this condition.

\section{Materials and methods Study design}

We performed this 9-week, randomized, double-blind, leftright axilla, placebo-controlled trial at the Department of Dermatology, Hospital Central of San Luis Potosí, México. Informed consent was obtained from subjects before entering the study, which was approved by the local ethics committee. This study is registered on the US National Institutes of Health Clinical Trial Register (NCT01542138).

Patients having axillary hyperpigmentation and attending our outpatient clinic were invited to participate. The luminance $\left(\mathrm{L}^{*}\right)$ value was measured by colorimetry to obtain an objective parameter of the brightness of axillary pigmentation, and those patients with differences between the adjacent skin and axillary area $>2.0$ were enrolled. Inclusion criteria were female gender, age 18-40 years, good health, and no topical, systemic, laser, or surgical treatment in the axillary area during the previous 6 weeks. Exclusion criteria were pregnancy, nursing, menopause, overweight, obesity, acanthosis nigricans, and presence of any systemic or pigmentation disorder. A medical history was obtained from each patient regarding age, occupation, time of onset, hair removal methods, deodorant/antiperspirant use, physical activity, and cleansing habits.

\section{Study interventions}

The topical study medications were put into similar containers, and the patients were randomly assigned in a double-blind manner to receive niacinamide $4 \%$, desonide $0.05 \%$ (Galderma, Courbevoie, France), or placebo cream on their axillae. Niacinamide cream was formulated by combining niacinamide powder (Spectrum, Gardena, CA) with Cetaphil ${ }^{\circledR}$ moisturizing cream (Galderma, Ontario, Canada) to yield a $4 \%$ concentration, while a Cetaphil cream without niacinamide was used as the placebo. A stability screen using high-performance liquid chromatography demonstrated that more than $90 \%$ of the active ingredient remained in the moisturizer 3 months after preparation. All subjects were instructed to apply a certain amount of the topical medication to a specified area at night (ie, $1 \mathrm{mg} / \mathrm{cm}^{2}$ ). Concomitant use of an antiperspirant product containing aluminum chlorohydrate $8 \%$ was allowed every morning, and usual hygiene measures were continued throughout the study period (ie, soaps, cleanser items). All adverse events were recorded. 


\section{Assessments}

\section{Colorimetric and clinical evaluation}

The treatments were administered for 9 weeks, with a baseline evaluation and follow-up at 3, 6, and 9 weeks. The primary outcome measure was reduction in axillary hyperpigmentation. Pigmentary changes were assessed objectively using a tristimulus colorimeter (Chromameter CR-300, Minolta, Osaka, Japan). Changes in coloration were examined by $\mathrm{L}^{*}$ (luminosity), where 100 is full white and 0 is total black. Erythema was evaluated using the $a^{*}$ axis which has values from 0 to 50 . Measurements were obtained after careful shaving of the axilla, which was done on the day prior to assessment. The axilla was divided into quadrants and the average of four measurements was used for analysis. Improvement was assessed by obtaining the $\mathrm{L}^{*}$ axis difference $\left(L^{*} \Delta\right)$ between the targeted axilla and a nonpigmented area $\left(\mathrm{L}^{*} \Delta=\right.$ axilla - periaxilla). The selected periaxillary control site was the area located at the intersection of the mid axillary line and the fifth intercostal space. The $\mathrm{a}^{*}$ axis was assessed in a similar manner. Clinical improvement was assessed by standardized digital photographic registration. Two independent observers performed a Physician Global Assessment, scored as poor ( $0 \%-25 \%)$, mild (26\%-50\%), good $(51 \%-75 \%)$, or excellent $(>75 \%)$.

\section{Histological samples}

Secondary outcome measures included histological evaluation of skin trauma (ie, epidermal basal membrane integrity and microhemorrhage), inflammatory cells, melanin content, and epidermal thickness. For these evaluations, we obtained a $3 \mathrm{~mm}$ punch biopsy at baseline and at the end of the study for each axilla. All samples were stained with hematoxylin and eosin to determine general features, with Fontana-Masson staining for evaluation of melanin content and Perl's iron staining for hemosiderin deposits.

To evaluate the contents of Langerhans cells, melanophages, and mature melanocytes, we used antibodies to CD1a, CD68, and NKI/Beteb, respectively. The integrity of the epidermal basal membrane was assessed using a collagen IV antibody. Sections $4 \mu \mathrm{m}$ in thickness were taken from frozen tissue fixed in acetone and then processed with monoclonal antibodies for CD1a, CD68 (SC-70761), NKI/ Beteb (SC-52704), and collagen IV (SC-59814, all sourced from Santa Cruz Biotechnology, Santa Cruz, CA). Working dilutions were obtained using trials with positive controls. The skin sections were incubated with serum blocker, and the primary antibodies per hour were then added, washing with an $\mathrm{HCl}$ buffer at $\mathrm{pH} 7.6$ for 20 minutes. After further washing with the same buffer, the sections were incubated for 30 minutes with a biotinylated secondary antibody and subsequently treated with an avidin-biotin-peroxidase complex (Vectastain Elite, Vector Laboratories, Burlingame, CA). The sections were developed with 3-amino-ethyl-carbazole for 3 minutes, washed in water, and counterstained with Mayer's hematoxylin.

\section{Image analysis}

To get a scanning view of the epidermis and dermis, every tissue section was captured with $10 \times$ and $40 \times$ magnification using a digital camera mounted on a microscope (CX31, Olympus, Tokyo, Japan) connected to a computer. Once captured, the images were processed using Image J v 1.44 software (National Institutes of Health, Bethesda, MD). The inflammatory infiltrate was quantified by two independent blinded observers aided by the cell counter function. The number of cells per $\mathrm{mm}^{2}$ was estimated for the entire specimen. The same procedure was used to count cells expressing NKI/Beteb, CD1a, and CD68. For quantification of melanin, the epidermal images were treated by channeling, deconvolution, and binary processing. ${ }^{27}$ The area involved was calculated and expressed as a percentage per $\mathrm{mm}^{2}$. The epidermal area was estimated by tracing its margins from the stratum granulosum to the dermal-epidermal junction, and the mean thickness was obtained by dividing the area along the horizontal length. ${ }^{27}$ To evaluate basal membrane integrity, collagen IV expression was evaluated as a percentage of absence or disruption in relation to its full depth.

\section{Statistical analysis}

We calculated that a sample size of 16 axillae per intervention would detect a relative difference of $10 \%$ in values on the $\mathrm{L}^{*}$ axis between the active treatments and placebo (ie, 56 in the treatment groups, 50 for the placebo), assuming a standard deviation of 5 , a $95 \%$ confidence interval, and a two-tailed $\alpha$ of 0.05 and $\beta$ of 0.8 . Therefore, 28 subjects with symmetric axillary hyperpigmentation were needed to ensure 56 evaluable hyperpigmented axillae, allowing a dropout rate of $15 \%$. Permuted block randomization was used to assess the effects of treatment on lesions. The statistical analysis was performed using analysis of variance with Bonferroni correction, $t$-test, $\chi^{2}$ test (Fisher's Exact test if $\mathrm{n}<5$ ), and correlation tests, and a level of statistical significance set at 5\%. The Physician Global Assessment was standardized using the kappa test of consistency. Tests were performed using JMP software version 8.0 (SAS Institute Inc, Cary, NC). 


\section{Results}

Twenty-four female patients with axillary hyperpigmentation were included. Their mean age was 21 (19-27) years and the mean duration of hyperpigmentation was $5.8(5-9)$ years. The skin phototypes of the sample were III (21\%), IV (46\%), and V (33\%). Shaving of the armpit area was the most common hair removal method, and used in $86 \%$. Daily cleansing of the area and use of an antiperspirant containing aluminum chlorohydrate was reported by all patients. None of the patients reported undertaking physical activity for more than 40 minutes per day. These data are summarized in Table 1.

\section{Colorimetric and clinical evaluation}

Reduction in hyperpigmentation of the axillae from baseline to the end of the study was significantly higher in the niacinamide and desonide groups than in the placebo group (analysis of variance, $P=0.03$ ). At 6 weeks, only desonide showed a significant improvement compared with placebo. However, at 9 weeks, the mean reduction in $\mathrm{L}^{*} \Delta$ values in the niacinamide and desonide groups was $8.9 \pm 4.6$, and $6.2 \pm 5.6$, respectively, compared with $11.1 \pm 4.6$ in the placebo group. Although both interventions were better than placebo, the difference between these agents was significant ( $t$-test, $P=0.002$ ), favoring the depigmenting effects of desonide. These data are shown in Figure 1.

At the conclusion of the trial, a significant reduction in the $\mathrm{a}^{*} \Delta$ value was only observed for the desonide-treated group in relation to placebo ( $t$-test, $P=0.003)$. Niacinamide did not

Table I Clinical features of the 24 female patients at baseline

\begin{tabular}{ll}
\hline Age (years), mean (SD) & $21.7 \pm \mathrm{I} .6$ \\
Skin phototype, $\mathrm{n}(\%)$ & $5(2 \mathrm{I})$ \\
III & $\mathrm{II}(46)$ \\
IV & $8(33)$ \\
V & \\
Duration of AHP (years) & $5.8 \pm \mathrm{I} .7$ \\
$\quad$ Mean (SD) & \\
Body mass index & $23.5 \pm 2.5$ \\
$\quad$ Mean (SD) & \\
Hair removal methods, $\mathrm{n}(\%)$ & $87 \%(2 \mathrm{I})$ \\
$\quad$ Axillary shaving & $8 \%(2)$ \\
$\quad$ Waxing & $4 \%(\mathrm{I})$ \\
$\quad$ Plucking & \\
Daily hygiene habits, $\mathrm{n}(\%)$ & $24(100)$ \\
$\quad$ Antiperspirant use & $24(100)$ \\
Cleansing & \\
Axillary colorimetry, mean (SD) & $51.2 \pm 5.3$ \\
L* & $9.1 \pm \mathrm{I} .2$ \\
\hline a*
\end{tabular}

Abbreviations: AHP, axillary hyperpigmentation; SD, standard deviation.

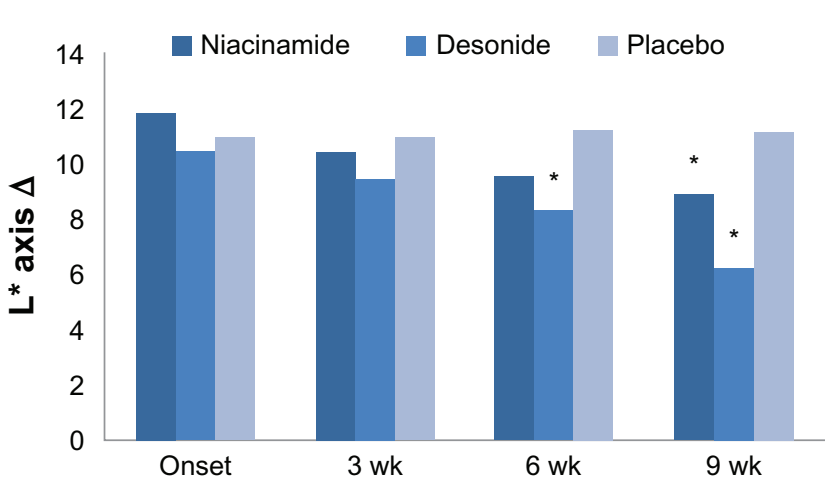

Figure I Effect of niacinamide $(n=16)$, desonide $(n=16)$, and placebo $(n=16)$ on the luminosity change $\left(\mathrm{L}^{*} \Delta\right)$ in axillae treated during the study.

Notes: The bar chart shows differences between the group means during the study. $* P \leq 0.05$, statistically significant compared with placebo. Both drugs were better than placebo at 9 weeks, but desonide improved the axillary hyperpigmentation better than niacinamide ( $t$-test, $P=0.002)$.

show large changes in this value compared with desonide and placebo. Concerning the Physician Global Assessment score at the end of the study, niacinamide was rated as excellent in $12 \%$, good in $12 \%$, moderate in $43 \%$, and mild in $31 \%$. In the desonide-treated axillae, the improvement was excellent in $12 \%$ of patients, good in $18 \%$, moderate in $31 \%$, and mild in $37 \%$. There was a poor to mild response to placebo in $90 \%$ of axillae. These data are shown in Figure 2. Therefore, although there was a range of responses from mild to excellent (68\% for niacinamide and $62 \%$ for desonide), these differences were significant because clinical improvement was only $37 \%$ for the placebo group $\left(\chi^{2}, P \leq 0.001\right)$. Clinical images graded as showing excellent improvement in response to niacinamide and desonide are shown in Figure 3. No side effects were reported during the trial for any of the interventions.

\section{Histological assessment}

Fontana-Masson staining showed that the amount of epidermal melanin was significantly decreased in the

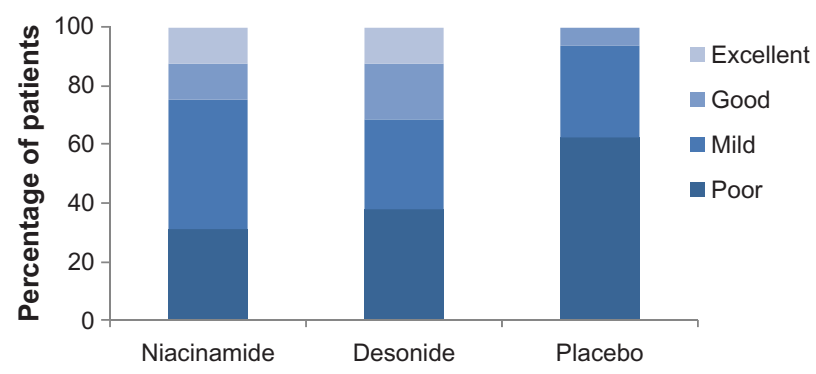

Figure 2 Physician assessment of improvement in axillary hyperpigmentation at the end of treatment (week 9).

Notes: The efficacy of niacinamide and desonide was rated equally for good and excellent response ( $P=0.5$, and $P=0.8, \chi^{2}$ test). The placebo response was significantly lower compared with both drugs for these categories $\left(P<0.001, \chi^{2}\right.$ test $)$. 

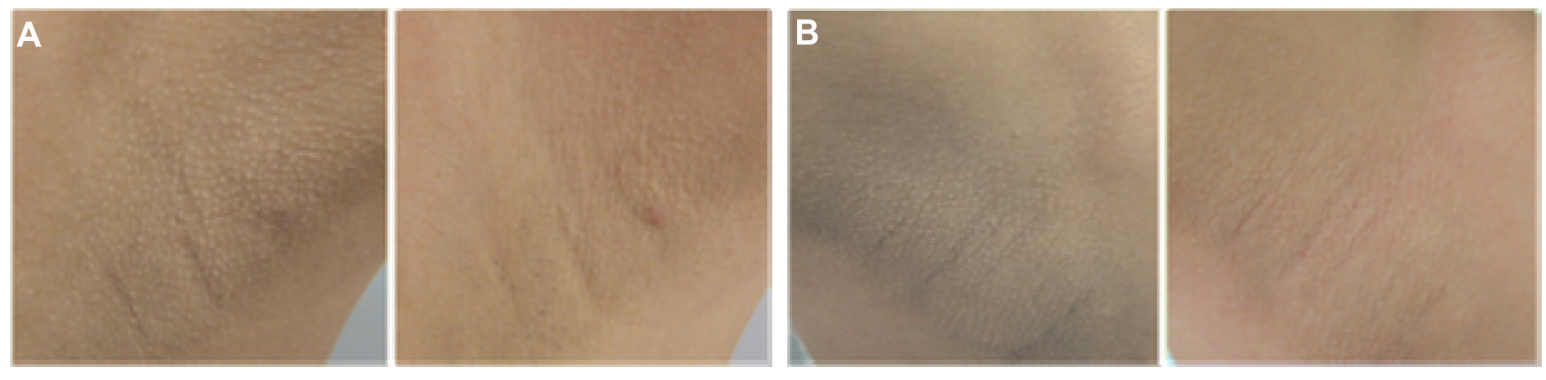

Figure 3 Photographs showing an excellent clinical response to treatment. (A) Axillae in a 22-year-old woman treated with niacinamide (left image). (B) The desonide-treated side in a 25 -year-old woman at baseline and after 9 weeks of therapy (right image).

niacinamide-treated axillae $(14.1 \pm 8.5$ versus $4.9 \pm 2.2$, $P<0.001)$. A similar reduction was seen in the desonidetreated axillae $(14.5 \pm 8.7$ versus $4.7 \pm 2.7, P<0.001)$. No difference was observed with placebo $(15.5 \pm 8.7$ versus $14.2 \pm 7.4, P=0.6)$. Hemosiderin deposits were negative using the Perl's iron stain in all specimens.

Staining for NKI/Beteb showed that the mean number of positive melanocytes overall at the end of the study were not significantly different compared with the initial counts for niacinamide ( $23 \pm 5$ versus $26 \pm 4, P=0.1$ ), desonide (24 \pm 6 versus $27 \pm 1, P=0.1$ ), or placebo (26 \pm 6 versus $23 \pm 7, P=0.1)$.

Results of hematoxylin and eosin staining revealed that treatment with niacinamide significantly decreased the mean number of mononuclear cells $/ \mathrm{mm}^{2}$ from 1585 to 1184 ( $t$-test, $P=0.03$ ). Desonide was also able to reduce this number from 1474 cells $/ \mathrm{mm}^{2}$ initially to 1044 cells $/ \mathrm{mm}^{2}$ at the end of the study ( $t$-test, $P=0.01)$.

CD1a staining demonstrated no significant change in the number of Langerhans cells for the three interventions at the end of the study. CD68 cell numbers were significantly reduced by niacinamide and desonide (from $6 \pm 2$ to $4 \pm 3$, $P=0.05$, and from $6 \pm 1$ to $4 \pm 2, P=0.01$, respectively), but not by placebo (from $5 \pm 1$ to $5 \pm 2, P=0.1$ ).

Assessment of collagen IV expression in the basal membrane zone revealed a discontinuous improvement from $39 \% \pm 21 \%$ initially to $24 \% \pm 14 \%$ at the end of treatment for niacinamide $(P=0.02)$. Desonide showed a greater improvement from $39 \% \pm 21 \%$ to $20 \% \pm 14 \%(P=0.005)$, and placebo remained unchanged ( $38 \% \pm 18 \%$ versus $30 \% \pm 17 \%, P=0.1)$.

Compared with baseline, microscopic evaluation of hematoxylin and eosin sections revealed that none of the interventions had induced a significant change in epidermal thickness by the end of the study. The data are summarized in Table 2, and are also shown in Figure 4.

At the conclusion of the study, we found a significant association between reduction in $L^{*} \Delta$ and collagen IV stain continuity in the epidermal basal membrane for desonide ( $r=0.6, P=0.01)$ but not for niacinamide $(r=0.24, P=0.38)$ or placebo $(r=0.02, P=0.92)$. Likewise, there was a direct relationship between the content of melanin stain and expression of collagen IV at the dermoepidermal junction for desonide ( $r=0.5, P=0.04)$ and placebo $(r=0.5, P=0.04)$, but not for niacinamide $(r=0.3, P=0.26)$. These findings are shown in Figure 5. With regard to the inflammatory infiltrate, we did not find a significant relationship between reduction of $\mathrm{L}^{*} \Delta$ or mononuclear, $\mathrm{CD} 1 \mathrm{a}$, and $\mathrm{CD} 68$ cell counts for any intervention, nor did we find a significant relationship between melanin content and mononuclear, CD1a, and CD68 cell counts.

\section{Discussion}

As far as we know, there are no previous randomized, controlled clinical trials exploring whether topical antiinflammatory drugs such as desonide and niacinamide offer clinical benefits in patients with axillary hyperpigmentation. Using both clinical and objective methods, we found evidence that both agents were able to reduce hyperpigmentation better than placebo, although desonide had a superior blanching effect.

Because inflammation is considered to be an associated condition, we looked for its gross presence and documented its modification by the study interventions. We found that niacinamide was able to reduce mononuclear and phagocytic cell infiltrates, as well as melanin expression, compared with baseline. Previous studies have shown that niacinamide limits the transfer of melanosomes to keratinocytes, ${ }^{21}$ reduces inflammatory cytokine levels, and decreases expression of major histological complex class II and adhesion molecules on immune cells. ${ }^{28,29}$ Other anti-inflammatory properties may be related to free radical scavenging, and suppression of NADdependent enzymes and inducible nitric oxide synthase..$^{28,29}$

On the other hand, desonide is a low potency corticosteroid with anti-inflammatory properties comparable with those 
Table 2 Changes in colorimetric values $\left(L^{*} \Delta, a^{*} \Delta\right)$, melanin content, mononuclear cells, NKI/Beteb, CDIa, CD68, collagen IV expression, and epidermal thickness in axillae treated with niacinamide, desonide, and placebo

\begin{tabular}{|c|c|c|c|c|c|c|c|c|c|}
\hline & \multicolumn{3}{|c|}{ Niacinamide } & \multicolumn{3}{|l|}{ Desonide } & \multicolumn{3}{|l|}{ Placebo } \\
\hline & Baseline & 9 weeks & $P$ & Baseline & 9 weeks & $P$ & Baseline & 9 weeks & $P$ \\
\hline $\mathrm{L}^{*} \Delta$ & $11.8 \pm 5.1$ & $8.9 \pm 4.6$ & $<0.001$ & $10.4 \pm 4.2$ & $6.2 \pm 5.6$ & $<0.001$ & $\mathrm{II} \pm 4.7$ & $\mathrm{II} . \mathrm{I} \pm 4.6$ & 0.9 \\
\hline$a^{*} \Delta$ & $1.3 \pm 2$ & $0.8 \pm 2.1$ & 0.1 & $1.2 \pm 1.9$ & $0.5 \pm 1.8$ & 0.003 & $1.4 \pm 2.2$ & $1.1 \pm 1.9$ & 0.7 \\
\hline Melanin & $\mid 4.1 \pm 8.5$ & $4.9 \pm 2.2$ & $<0.001$ & $14.5 \pm 8.7$ & $4.7 \pm 2.7$ & $<0.001$ & $15.5 \pm 8.7$ & $14.2 \pm 7.4$ & 0.6 \\
\hline NKI/Beteb & $23.1 \pm 5.9$ & $26.2 \pm 4.3$ & 0.1 & $24.3 \pm 6.4$ & $27.2 \pm 1.8$ & 0.1 & $26.5 \pm 6.2$ & $23.1 \pm 7.5$ & 0.1 \\
\hline Mononuclear cells & $1585 \pm 603$ & $1184 \pm 417$ & 0.03 & $1474 \pm 589$ & $1044 \pm 281$ & 0.01 & $1630 \pm 60 \mid$ & $1543 \pm 532$ & 0.6 \\
\hline CDla & $35.6 \pm 10.4$ & $27.1 \pm 10.2$ & 0.9 & $29.6 \pm 12.1$ & $29.1 \pm 14.6$ & 0.1 & $30.3 \pm 11.8$ & $28.3 \pm 13.6$ & 0.7 \\
\hline CD68 & $6.4 \pm 2$ & $4.4 \pm 3.2$ & 0.05 & $6 \pm 1.9$ & $4.2 \pm 2.5$ & 0.03 & $5.9 \pm 1.8$ & $5.2 \pm 2.7$ & 0.4 \\
\hline Collagen IV & $39 \pm 21$ & $24.4 \pm 14.4$ & 0.02 & $39.7 \pm 21.6$ & $20.1 \pm 14.5$ & 0.005 & $38.5 \pm 18.5$ & $30.1 \pm 17.2$ & 0.1 \\
\hline Epidermal thickness & $75.4 \pm 37.8$ & $73.3 \pm 38.1$ & 0.8 & $68.1 \pm 36.7$ & $75.3 \pm 38$ & 0.5 & $69.7 \pm 32.7$ & $76.9 \pm 35.1$ & 0.5 \\
\hline
\end{tabular}

Note: Data are shown for each intervention at baseline and at the end of the study. Data are expressed as the mean \pm standard deviation. Melanin (Fontana-Masson staining) represents the fraction (\%) stained per $\mathrm{mm}^{2}$ of epidermis. Inflammatory cells and positive for CDI, CD68, and NKI/Beteb antibodies were estimated in counts/mm ${ }^{2}$ for the whole specimen. Collagen IV was measured as a relative percentage of disruption. Epidermal thickness is in $\mu \mathrm{m}$.

of nonfluorinated corticosteroids. ${ }^{26}$ Corticosteroids are the mainstay of treatment for dermatitis and reducing inflammation, pruritus, pigmentation, and vasodilatation. ${ }^{30}$ Desonide showed a similar pattern to that of niacinamide, reducing mononuclear and phagocytic cells as well as epidermal melanin levels. The hypopigmentation achieved by desonide could be theoretically related to its anti-inflammatory properties, although it has been shown that corticosteroids, by some unknown mechanism, interfere with synthesis of melanin in smaller melanocytes. ${ }^{30}$

Interestingly, in addition to the associated inflammatory cell infiltrates, we found a physical discontinuity of the

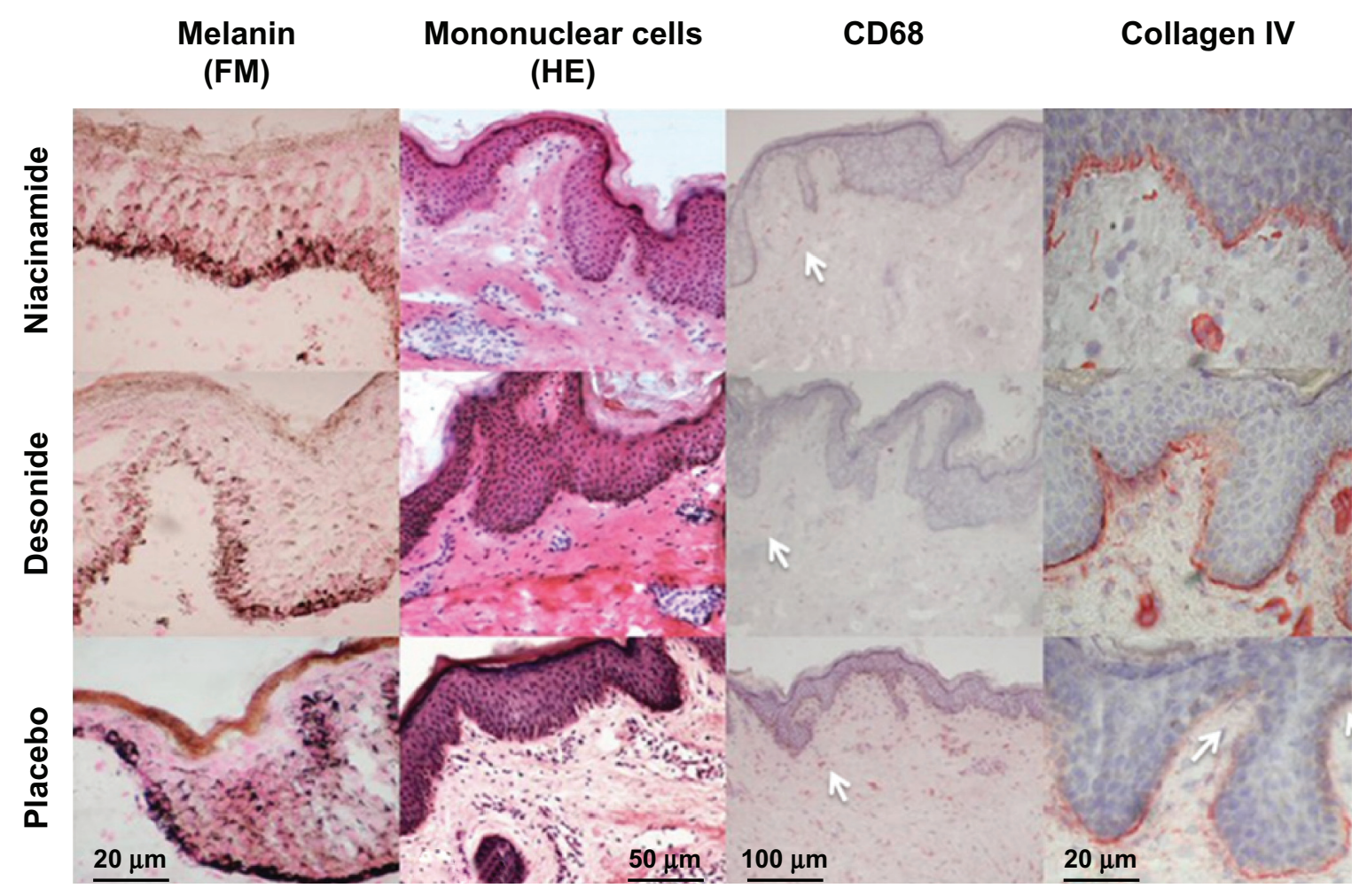

Figure 4 Reduction of epidermal melanin content (Fontana-Masson staining, 400x) after niacinamide and desonide, compared with placebo (first row).

Notes: Shown in the second row are representative examples of skin tissues stained with hematoxylin and eosin (200x) where numbers of mononuclear cells are more abundant in the placebo group. Immunohistochemical staining of skin tissues for CD68 cells (I00x) and collagen type IV (400x) in the third and fourth row showing a reduction of CD68 expression and increased basal membrane continuity for niacinamide and desonide compared with placebo. Collagen IV interruption sites and CD68 cells are pointed out with arrowheads. Bars show approximate measures.

Abbreviations: HE, hematoxylin and eosin staining; FM, Fontana-Masson staining. 

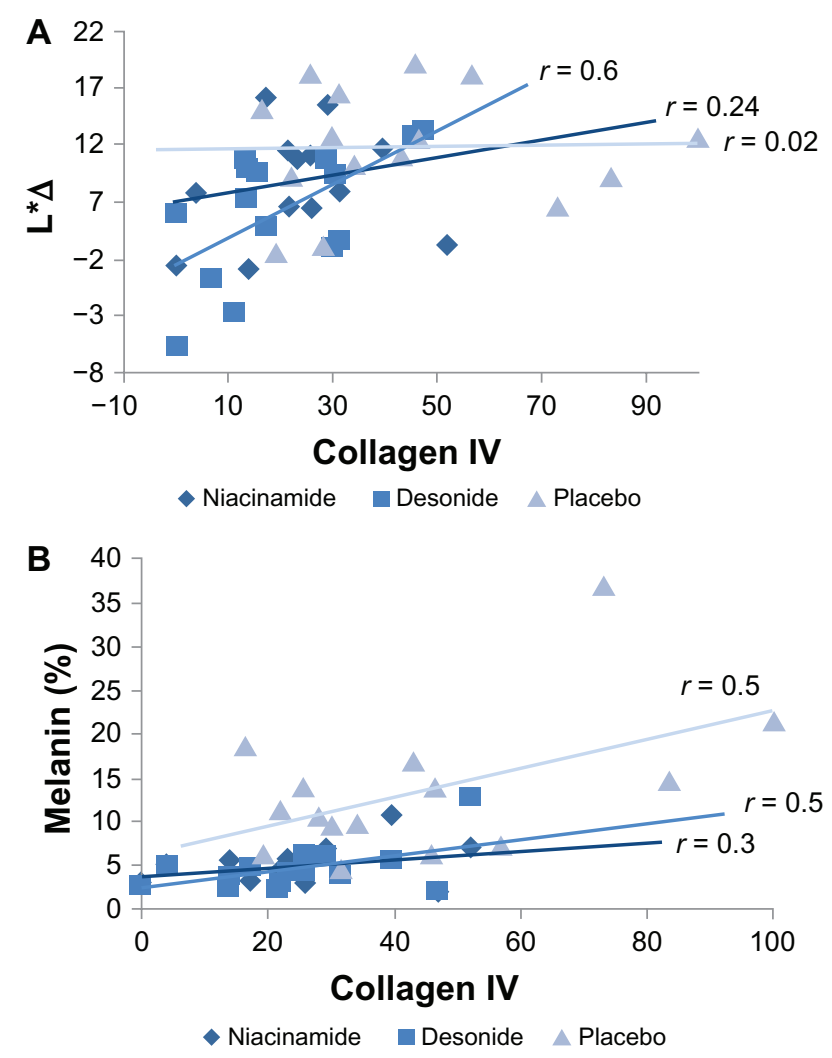

Figure 5 (A) Relationship between values in luminosity differences $\left(L^{*} \Delta\right)$ of the affected axillae, and the percent of basal membrane discontinuity expressed as collagen IV staining for the interventions at the end of the study. A significant association was only evident for desonide $(P=0.01)$. (B) Relationship between melanin content by Fontana-Masson staining and collagen IV expression for each intervention at the conclusion of the study.

Note: The association was significant for desonide and placebo ( $P=0.04$, for both).

epidermal basal membrane which, importantly, improved after exposure to both drugs, and was more evident in the desonide group. This disruption of the basal membrane could be primarily or indirectly conditioned by mechanical aggression of the axillary area. We suggest that desonide could reduce the inflammatory response that enhances disruption of the basal membrane, or even block mechanisms that delay its recovery. We did not find any changes in melanocyte count initially or after any of the interventions, so melanogenesis probably depends on increased synthesis of melanin and not on a change in numbers of pigmented cells. All these findings suggest a relationship between trauma, local inflammation, and induction of melanogenesis in axillary hyperpigmentation.

Side effects, including local erythema, burning, pruritus, infection, and skin atrophy, were absent during the trial. Drawbacks to the long-term use of topical corticosteroids include atrophic skin changes, immunosuppression, steroid acne, and tachyphylaxis. ${ }^{30}$ However, we did not observe any of these during the 9 weeks of administration of desonide, despite the well-known vasoconstrictor effect observed by colorimetry during the trial. These findings suggest that both drugs have a safe profile for use in the axillae.

Although the frequency of axillary hyperpigmentation is unknown, it is a common complaint among females of dark complexion from tropical areas throughout the world ${ }^{8}$ Axillary hyperpigmentation has not been extensively studied due to its predominantly cosmetic nature and lack of any relevant health implications. Based on the results of our study, we suggest that niacinamide and desonide have some value in the treatment of axillary hyperpigmentation. We assume that associated antiperspirant use during the trial was a negligible factor, considering that all the involved axillae administration were exposed under similar conditions to commercial concentrations of aluminum chlorohydrate, and we observed a clinically and histologically noticeable benefit of the interventions compared with placebo. However, limitations of our trial include its single-center nature, inclusion of a relatively small number of patients, comprising only young women.

Previous publications have suggested that postinflammatory hyperpigmentation is improved by use of anti-inflammatory and depigmenting agents, ${ }^{7,12,14,16-19,31}$ but few have objectively evaluated post-inflammatory hyperpigmentation at the histological level. ${ }^{14}$ Our results indicate that both drugs are capable of reducing mononuclear and phagocytic cell infiltrates and repairing the fragmented epidermal basal membrane, thus reducing melanin expression. Further investigation is necessary to expand these findings concerning an impaired basal membrane, the inflammation process surrounding it, and enhancement of melanin synthesis.

\section{Acknowledgment}

Financial support for this research was provided by the Departments of Dermatology and Pathology at the Hospital Central Dr Ignacio Morones Prieto, San Luis Potosí, México.

\section{Disclosure}

The authors report no conflicts of interest in this work.

\section{References}

1. Alexis AF, Sergay AB, Taylor SC. Common dermatologic disorders in skin of color: a comparative practice survey. Cutis. 2007;80: 387-394.

2. Papa CM, Kligman AM. The behavior of melanocytes in inflammation. J Invest Dermatol. 1965;45:465-473.

3. Mottaz JH, Thorne EG, Zelickson AS. Response of the epidermal melanocyte to minor trauma. Arch Dermatol. 1971;104:611-618.

4. Tomita Y, Maeda K, Tagami H. Melanocyte-stimulating properties of arachidonic acid metabolites: possible role in postinflammatory pigmentation. Pigment Cell Res. 1992;5:357-361. 
5. Lamel SA, Rahvar M, Maibach HI. Postinflammatory hyperpigmentation secondary to external insult: an overview of the quantitative analysis of pigmentation. Cutan Ocul Toxicol. 2012;32:67-71.

6. Al-Aboosi M, Abalkhail A, Kasim O, et al. Friction melanosis: a clinical, histologic, and ultrastructural study in Jordanian patients. Int J Dermatol. 2004;43:261-264.

7. Callender VD, St Surin-Lord S, Davis EC, Maclin M. Postinflammatory hyperpigmentation: etiologic and therapeutic considerations. Am J Clin Dermatol. 2011;12:87-99.

8. James AG, Pople JE, Parish WE, Moore AE, Dunbar N. Histological evaluation of hyperpigmentation on female Filipino axillary skin. Int J Cosmet Sci. 2006;28:247-253.

9. Weisberg NK, Greenbaum SS. Pigmentary changes after alexandrite laser hair removal. Dermatol Surg. 2003;29:415-419.

10. Magaña M, Herrera-Goepfert R. Friction hypermelanosis: other variants. J Am Acad Dermatol. 2002;47:454.

11. Pincelli C, Magni R, Motolese A. Pigmented contact dermatitis from deodorant. Contact Derm. 1993;28:305-306.

12. Cook-Bolden FE, Hamilton SF. An open-label study of the efficacy and tolerability of microencapsulated hydroquinone $4 \%$ and retinol $0.15 \%$ with antioxidants for the treatment of hyperpigmentation. Cutis. 2008;81:365-371.

13. Grimes PE. Managment of hyperpigmentation in darker racial ethnic groups. Semin Cutan Med Surg. 2009;28:77-85.

14. Bulengo-Ransby SM, Griffiths CE, Kimbrough-Green CK, et al. Topical tretinoin (retinoic acid) therapy for hyperpigmented lesions caused by inflammation of the skin in black patients. N Engl J Med. 1993;328: 1438-1443.

15. Jacyk AK, Mpofu P. Adapalene gel $0.1 \%$ for topical treatment of acne vulgaris in African patients. Cutis. 2001;68:48-54.

16. Grimes P, Callender V. Tazarotene cream for postinflammatory hyperpigmentation and acne vulgaris in darker skin: a double-blind, randomized, vehicle-controlled study. Cutis. 2006;77:45-50.

17. Lowe NJ, Rizk D, Grimes P, Billips M, Pincus S. Azelaic acid 20\% cream in the treatment of facial hyperpigmentation in darker-skinned patients. Clin Ther. 1998;20:945-959.

18. Burns RL, Prevost-Blank PL, Lawry MA, Lawry TB, Faria DT, Fivenson DP. Glycolic acid peels for post- inflammatory hyperpigmentation in black patients: a comparative study. Dermatol Surg. 1997;23: 171-174.
19. Ahn HH, Kim IH. Whitening effect of salicylic acid peels in Asian patients. Dermatol Surg. 2006;32:372-375.

20. Polder KD, Landau JM, Vergilis-Kalner IJ, Goldberg LH, Friedman PM, Bruce S. Laser eradication of pigmented lesions: a review. Dermatol Surg. 2011;37:572-595.

21. Hakozaki T, Minwalla L, Zhuang J, et al. The effect of niacinamide on reducing cutaneous pigmentation and suppression of melanosome transfer. Br J Dermatol. 2002;147:20-31.

22. Bissett DL, Miyamoto K, Sun P, et al. Topical niacinamide produces yellowing, wrinkling, red blotchiness, and hyperpigmented spots in aging facial skin. Int J Cosmet Sci. 2004;26:231-238.

23. Cosmetic Ingredient Review Expert Panel. Final report of the safety assessment of niacinamide and niacin. Int J Toxicol. 2005;24 Suppl 5: $1-31$

24. Navarrete-Solís J, Castanedo-Cázares JP, Torres-Álvarez B, et al. A double-blind, randomized clinical trial of niacinamide $4 \%$ versus hydroquinone $4 \%$ in the treatment of melasma. Dermatol Res Pract. 2011;2011:379173.

25. Takiwaki H, Shirai S, Kohno H, Soh H, Arase S. The degrees of UVB-induced erythema and pigmentation correlate linearly and are reduced in a parallel manner by topical anti-inflammatory agents. J Invest Dermatol. 1994;103:642-646.

26. Kahanek N, Gelbard C, Hebert A. Desonide: a review of formulations, efficacy and safety. Expert Opin Investig Drugs. 2008;17:1097-1104.

27. Torres-Álvarez B, Mesa-Garza IG, Castanedo-Cázares JP, et al. Histochemical and immunohistochemical study in melasma: evidence of damage in the basal membrane. Am J Dermatopathol. 2011;33: 291-295.

28. Ungerstedt JS, Blomback M, Soderstrom T. Nicotinamide is a potent inhibitor of proinflammatory cytokines. Clin Exp Immunol. 2003;131: 48-52.

29. Biedroń R, Ciszek M, Tokarczyk M, et al. 1-Methylnicotinamide and nicotinamide: two related anti-inflammatory agents that differentially affect the functions of activated macrophages. Arch Immunol Ther Exp. 2008;56:127-134

30. Hengge UR, Ruzicka T, Schwartz RA, Cork MJ. Adverse effects of topical glucocorticosteroids. J Am Acad Dermatol. 2006;54:1-15.

31. Grimes PE. A microsponge formulation of hydroquinone $4 \%$ and retinol $0.15 \%$ in the treatment of melasma and postinflammatory hyperpigmentation. Cutis. 2004;74:362-368.
Clinical, Cosmetic and Investigational Dermatology

\section{Publish your work in this journal}

Clinical, Cosmetic and Investigational Dermatology is an international, peer-reviewed, open access, online journal that focuses on the latest clinical and experimental research in all aspects of skin disease and cosmetic interventions. All areas of dermatology will be covered; contributions will be welcomed from all clinicians and

\section{Dovepress}

basic science researchers globally. This journal is indexed on CAS The manuscript management system is completely online and includes a very quick and fair peer-review system, which is all easy to use. Visit http://www.dovepress.com/testimonials.php to read real quotes from published authors. 